Athens Journal of Humanities \& Arts - Volume 4, Issue 1 - Pages 35-60

\title{
Representation of Trauma in Contemporary Arts
}

\author{
By Dumith Kulasekara*
}

This paper attempts to explore the theme of Trauma and its representation in Contemporary Art. In particular, analyzing the concept of trauma with its origin as a term in human history, the paper will bring a comprehensive understanding of the human body and psyche as a subject and content of the works produced in Contemporary Visual Arts. On this basis, the paper will be an extensive discussion of the representation of physical and psychological traumas in works of art. In fact, the paper will attempt to analyze how the theme has become a hidden meaning of some of the works while the paper will bring the theme into a discursive space by investigating the field of Contemporary Visual Arts including its different practices such as body art and performance, new media art, installation, happening art, etc. Significantly, another aim of the paper is to discuss the theme by contextualizing on visual art practices as made by both male and female artists. This means that the paper becomes critical on the point of view in exploring the theme on the basis of gender identity. Therefore, this research includes a critical discussion of trauma and gender identity. Furthermore, the paper will broaden its analytical sphere with cultural and philosophical concepts such as psychoanalysis, gender and other visual cultural theories. At the end of this paper, the research includes the author's own experience as an artist who has been working on the themes trauma and gender for nearly fifteen years. Furthermore, although the paper focuses on Contemporary Art particularly, it will also provide information of different periods of the Art History in contextualizing the theme and its representation in Contemporary works of Art.

"The representation of Trauma in Contemporary Arts" is a part of the research that $\mathrm{I}$ have been doing for more than ten years in my career as an artist. In this sense, this research is merely not only a text based research rather it is a visual based research.

The investigation of the theme of trauma represented in the works of art can be discussed in many ways. Sometimes it has to do with the content or the subjects of the works in which trauma could be both directly and indirectly present. Sometimes it has to do with the history and the background or the context of the works that could exist as underlying reasons for the origin of those works. Which also provides a psycho-iconography for their works. In the research, I will analyze the works focusing on their contents, contexts, subject matters, the materials and also the gender identity of the artists who make works of art. In a broad sense, the concept of trauma seems more related to the body. But, at the same time, the trauma has a

\footnotetext{
* Lecturer, University of the Visual and Performing Arts, Sri Lanka.
} 
significant connection with the psyche and the subject. In this sense, my approach is to investigate the presence of trauma in the art works in the forms of figuration, the abstraction, the deformation and also the minimalism.

In the contemporary art practice, it significantly marks that the body and the conception of the body become a dominant discourse in representational and non-representational art. In fact, in contrast to the Greek and Roman art where the body is celebrated as a divine spirit and transcendental, contemporary art brings new ways of understanding and interpretation of the body - psyche relation within the contemporary contexts of human life.

\section{What is Trauma?}

The term is initially used in the field of medicine in regarding the examination of the body which means opening the surface - skin and going deep into the interior of the body. The etymology of the terms takes us back to the Greek history in the $17^{\text {th }}$ century. Where the concept of trauma is associated with the meaning of both body and psychic wounding or piercing. Within the contemporary context, analyzing the concept of trauma, Grisellda Pollock suggests five defining features of trauma; perpetual presentness, permanent absence, irrepresentibility, belatedness and transmissibility. ${ }^{1}$ Sometimes, the nature of trauma has possibilities to connect the subject person who encountered by the thing unknown to the past where the thing affected. A traumatized person carries an impossible history within them or becomes the symptom of a history that they cannot entirely possess. ${ }^{2}$ The thing that is beyond the dimension of the thinking which encounters the subject with a shock can create a psychic trauma. In the Lacanian psychoanalytical sense, the thing that is beyond understanding or beyond reality - the Symbolic and the Imaginary, is called the Real which can be considered as the trauma. The inability to totally understand the event has a connection to the concept of trauma which can also link to the notion of the sublime in some way. In some sense, the events like war and terrorism become encounters that also could be represented in the form of sublime and as another way of the presence of the trauma. ${ }^{3}$ Significantly, the most intrinsic nature of the historical trauma is that it could be projected onto the future rather than to the past where the event happened. While talking about the

1. Grisellda Pollock, After Affect - After Image: trauma and aethetic transformation in the virtual museum (New York: Manchester University, 2013), 2.

2. __ Differencing the Canon; Feminist Desire and the writing of art Hisotries (New York: Routledge, 1999), 108.

3. Chritine Battersby, The Sublime, Terror and Humnan Difference (New York: Routledge, 2007), 194. 
event of the 9/11 (Figure 1) Derrida states this nature as one of the main characters of the trauma. The ordeal of the event has as its tragic correlates not what is presently happening or what has happened in the past but the precursory signs of what is threatened to happen. ${ }^{4}$

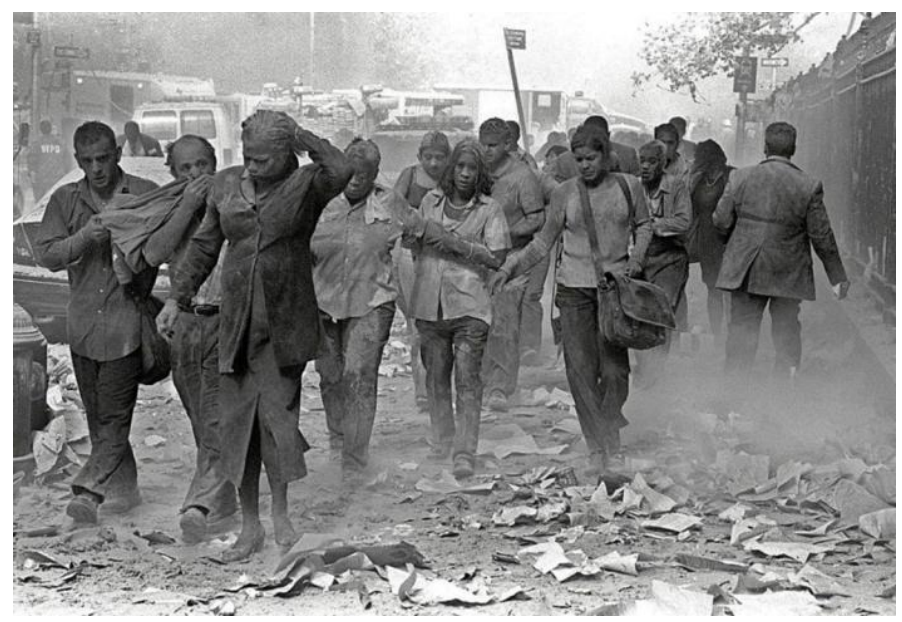

Figure 1. The World Trade Center in New York City, on September 11, 2001 - AP Photo/Gulnara Samoilova

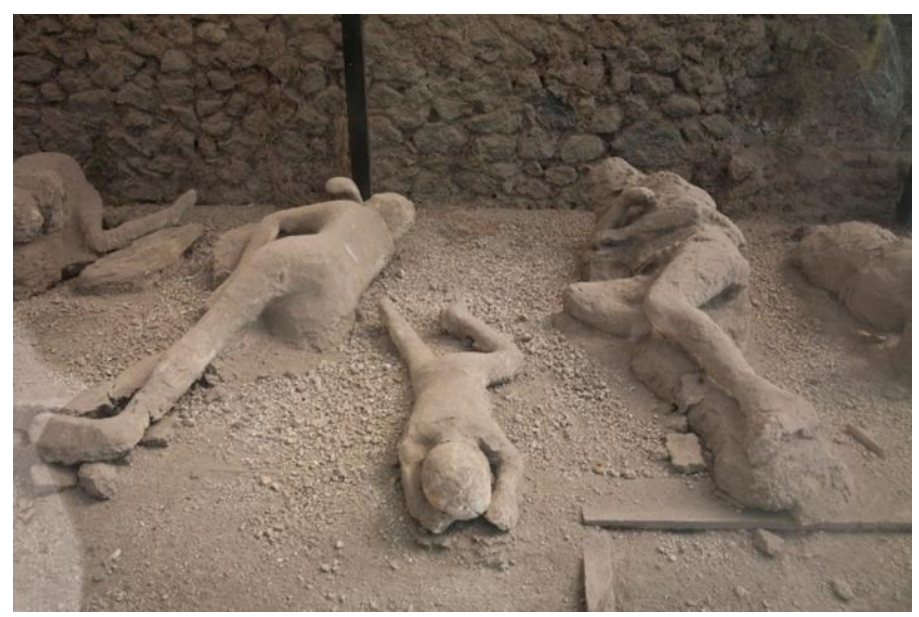

Figure 2. Garden of the Fugitives, plaster cast,....?

For an example, the destruction of the city of the Pompeii (Figure 2) as it is a trauma itself later gives a visual sense of a transgression of the bodypsyche relation to many contemporary artists for their own art practices. So, this material reminiscence has provided a sense of aesthetic expression that can be found in the works of artists like Anthony Gromely (Figure 3), Michale Oker Doner (Figure 4), Geroge Segal (Figure 5). In fact, this physical transformation evokes senses of both psychic and physical trauma. In

4. Ibid., 195. 
addition, The third of the May (Figure 6) by Francesco Goya, The Raft of Medusa (Figure 7) by Theodore Gericault and the Guernica (Figure 8) by Pablo Picasso are some of the visual evidences that we have in Art History that speak of the historical traumas.

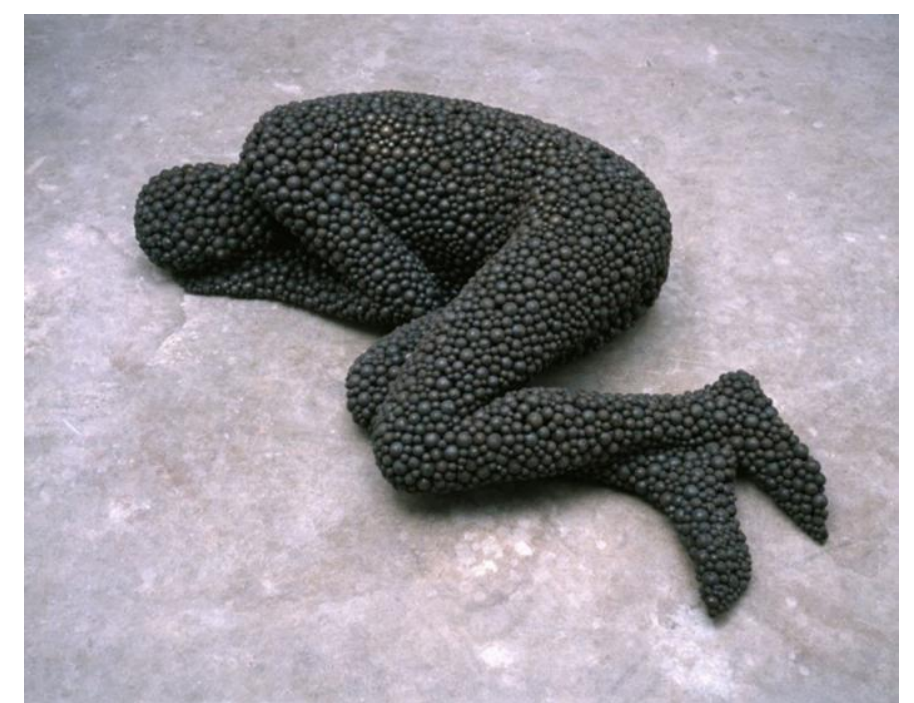

Figure 3. Antony Gormely, Bodies at rest 1, 2000 chrome balls, $33 \mathrm{~cm} \times 130 \mathrm{~cm} \times$ $170 \mathrm{~cm}$

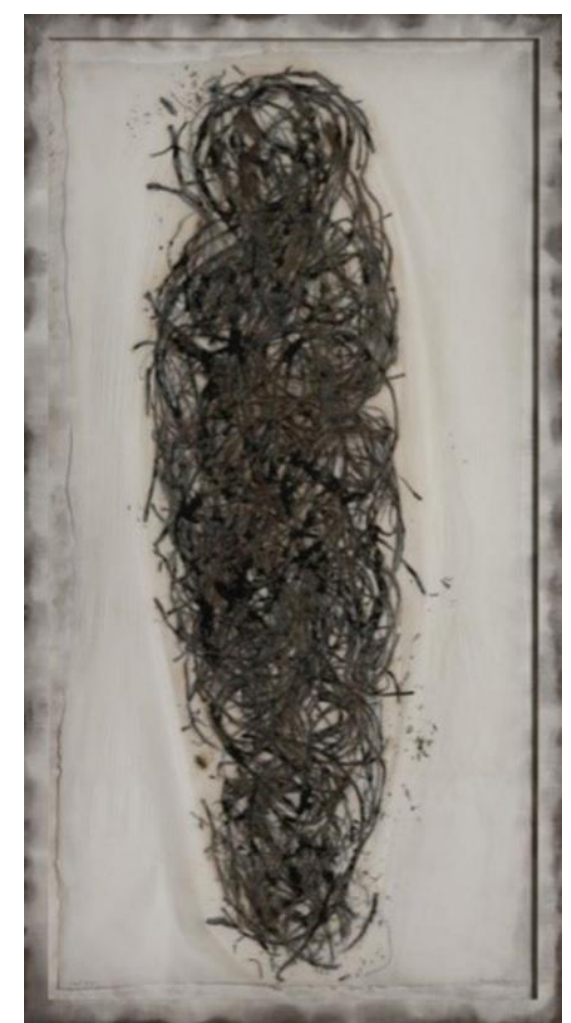

Figure 4. Michael Oka Doner, Corpus origin, 2014 


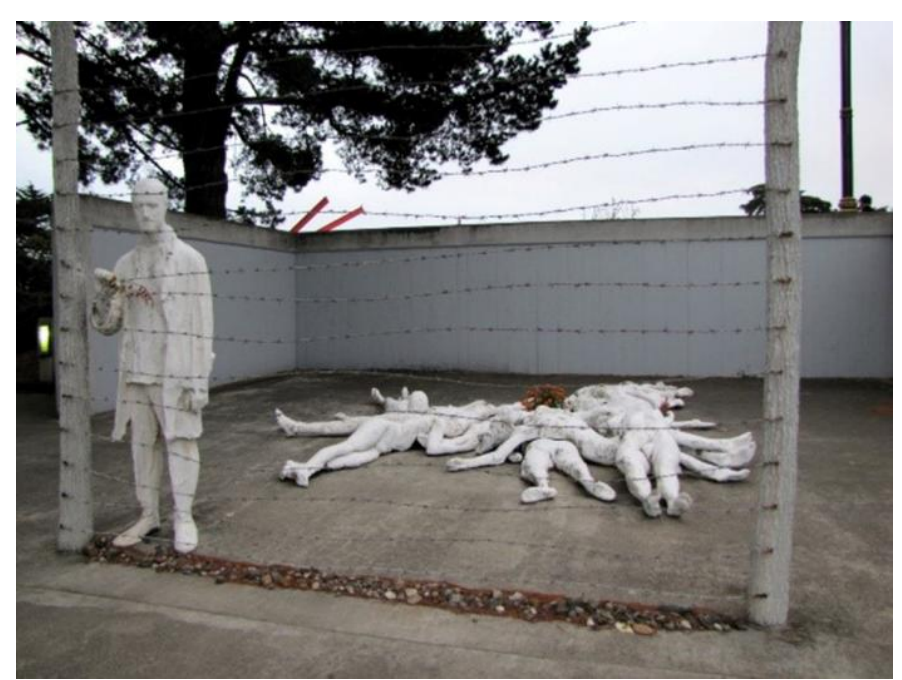

Figure 5. George Segal, the holocaust, 1984

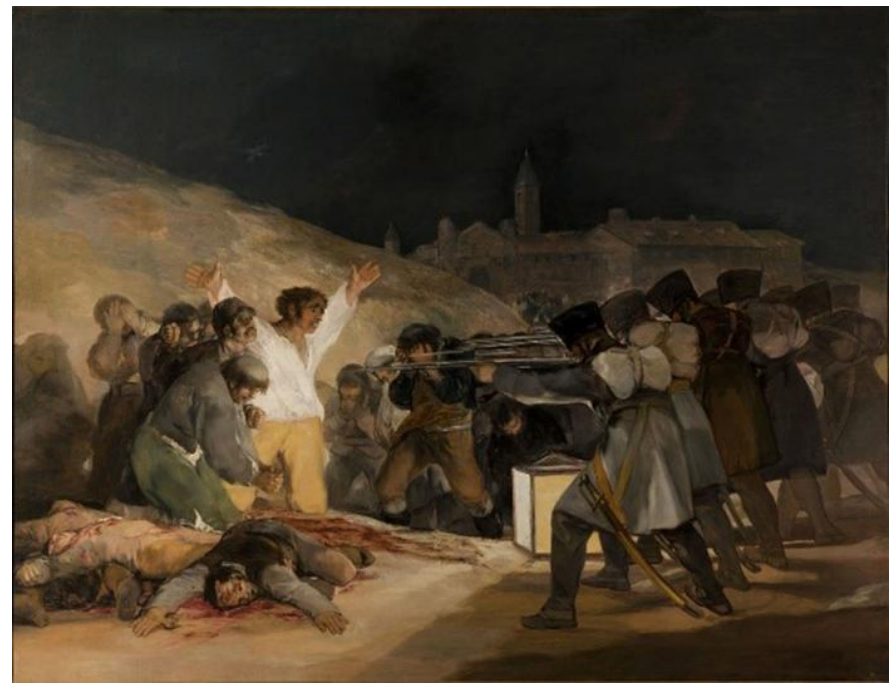

Figure 6. Francisco Goya, Third of May, 1814

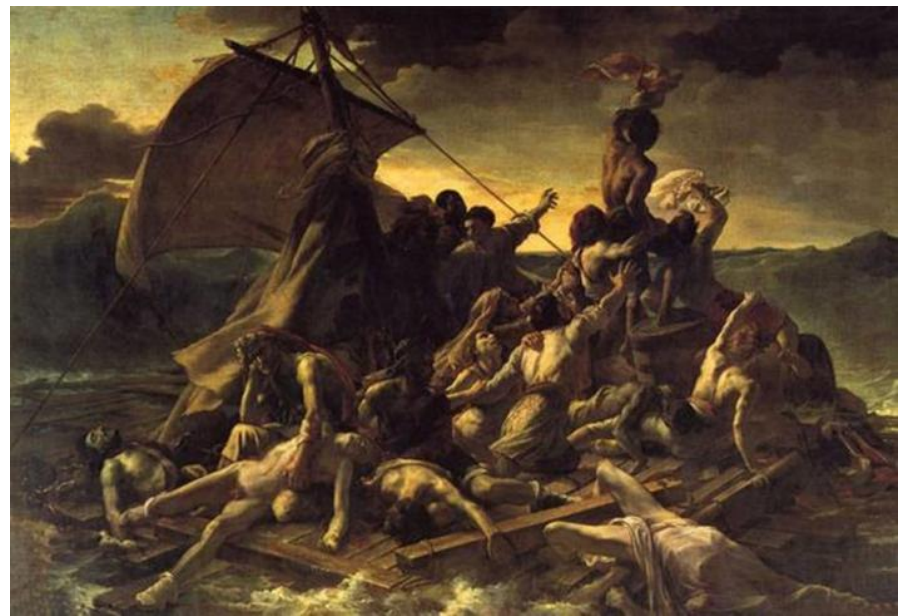

Figure 7. Theodore Gericault, The Raft of the Medusa,1818-1819 


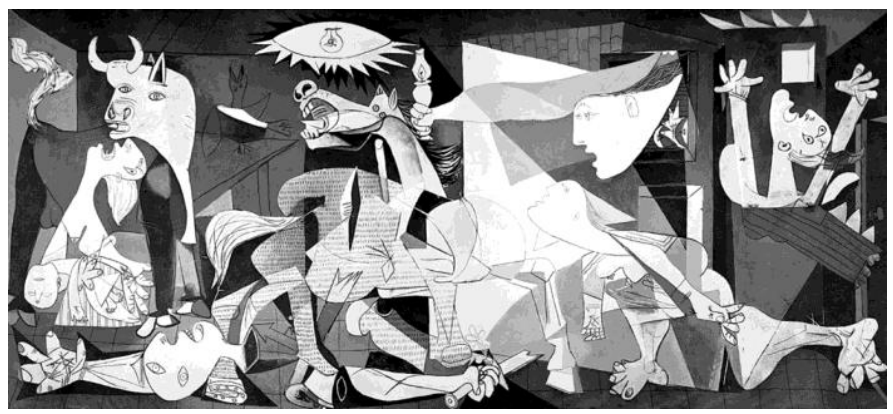

Figure 8. Pablo Picasso, Guernica, 1937

\section{Trauma Presence}

This section is dedicated to examine the presence of trauma in the physical and psychical forms in the works of art. By beginning to discuss the presence of the trauma in the work titled Special Concept waiting (Figure 9) by Lucio Fontana, the main argument is that the trauma becomes an inevitable meaning of this particular works.

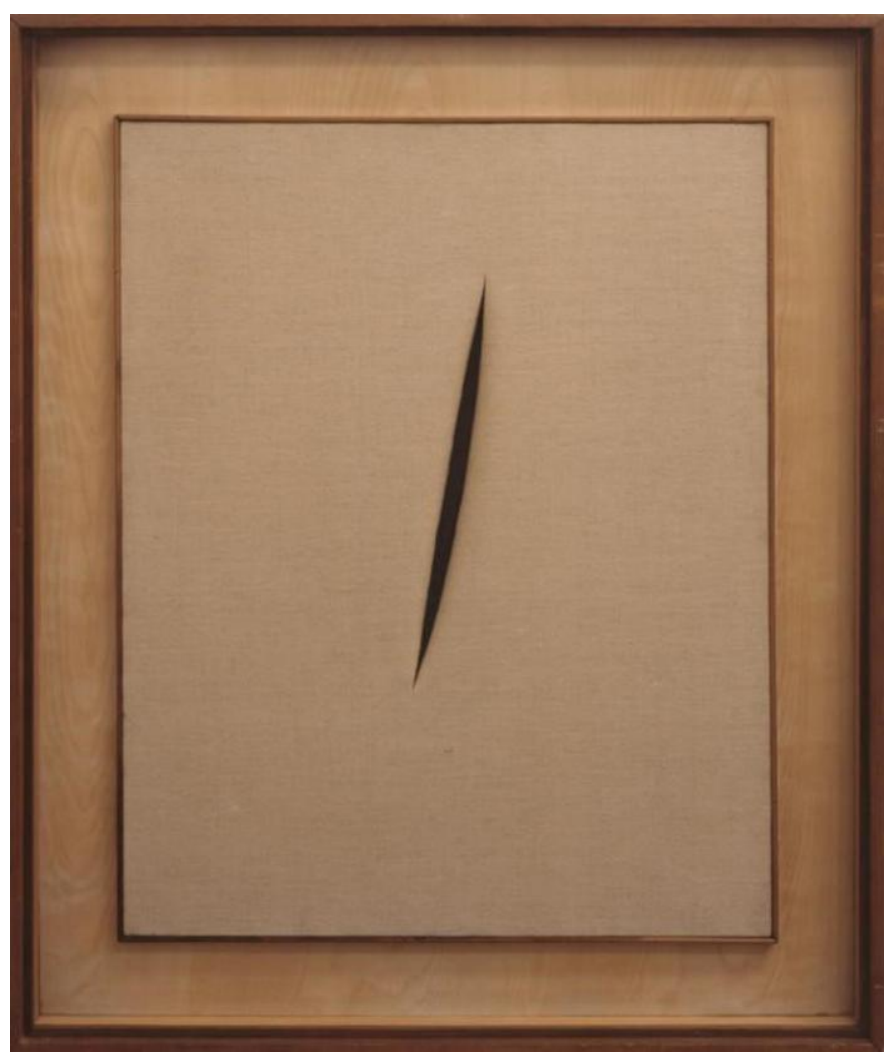

Figure 9. Lucio Fontana, Spatial Concept Waiting, 1960 
In this work he is not bringing figuration in literal sense, but abstractly, diagonally wounding a shield, a surface like a skin what he explores has an association with the work titled Doubting Thomas (Figure 10) by Caravaggio. In a way, Luciano's work is an intensely simplification of the presence of trauma in Caravaggio's painting. So, what this cut means is that it could be a wound, the mouth, the anus or also a sign of the castration. Significantly, the actual act of the work produces a sense of wildness which can make the trauma present in that way. In addition, Fontana's work as abstraction has an inherent power to represent the sensuousness of figuration. So, at this point, it can be said that this work has a duality of the presence and absence of trauma by appearing it in a literal sense and disappearing it as a representational.

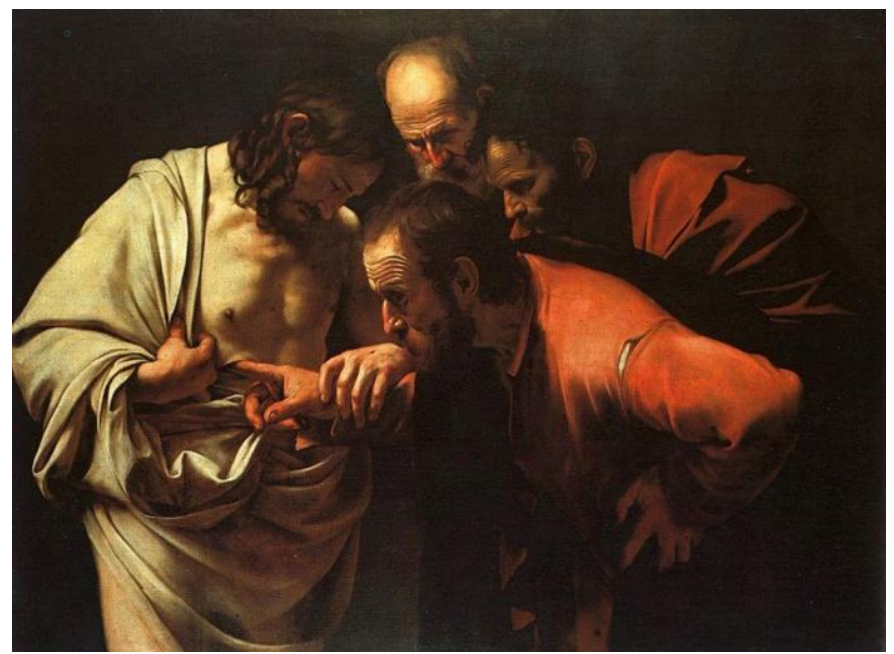

Figure 10. Caravaggio, Doubting Thomas, 1601-1602

In fact, the works by Michele Oka Doner (Figure 4) represent the bodies that significantly imply a transgression of both its subjective and objectively presences within the time of the life. Also, these material, and sense of forms express the nature of the bodies that transforms into the death. In fact, these shields seem as a representation of traces of some memories, in this context, the memories of her childhood which links to the geographical area that she grew up. The argument on these works is that they become trauma in terms of the sense that they evoke by going inside into the form from the surface shield of the skin - the earth as it is a metaphor of her memories takes her back to the past traces. In this sense, they also produce a feeling of the body without organs, which in fact gives a sense of trauma within the incompleteness of their presence. The body without organs is thus defined by an indeterminate organ.... In the exploring the theme on the bodily form, the history of the flesh represented in the works of art are still significant. The idea of the flesh

5. Gilles Deleuze, Francis Bacon; The logic of Sensation (Mineapolis: University of Minnesota Press, 2004), 41. 
that lies on the structure of the body has been changed both conceptually and perceptually over the years. From the level of the highest beauty of the ideal flesh (Figure 11) to the contemporary representation of the fragile and visceral presence of the flesh (Figure 12) which is ultra - real in a sense, it is able to create its own narration of the historical transformation of the relationship between the subject and object.

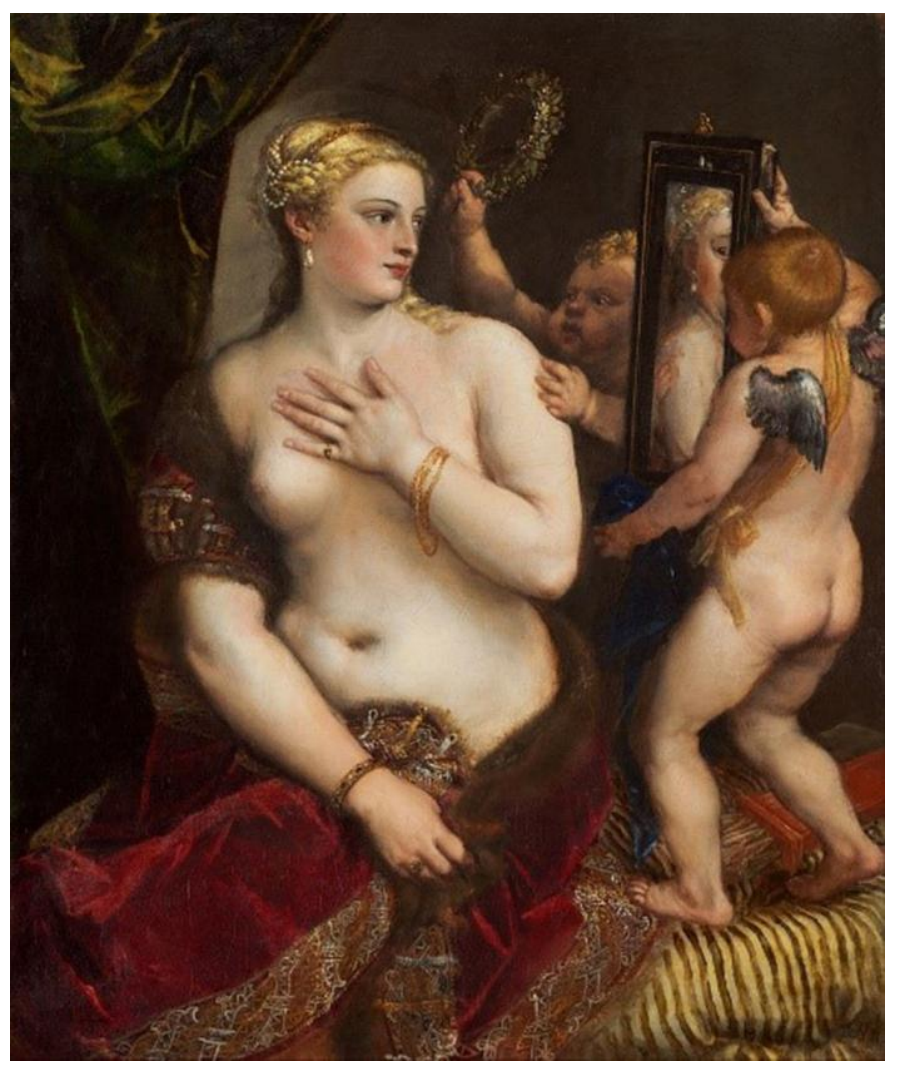

Figure 11. Titian, Venus with a mirror, 1555

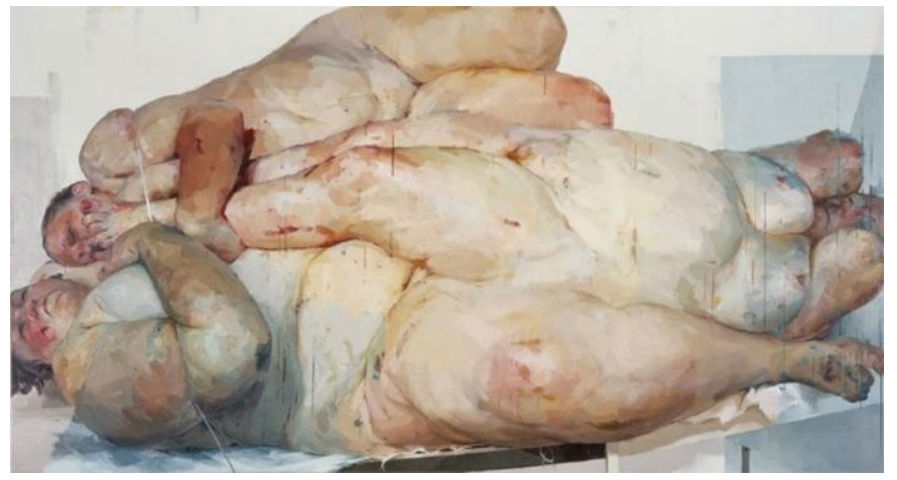

Figure 12. Jenny Saville, Fulcrum, 1999

In this sense, the trauma is also represented with the contemporary notion of the flesh which becomes very closer to the Real that can cause a shock of the viewer, than the representation of the real in Gustave Courbet's sense (Figure13). 
Which also occurs in a highly controversial place in the history of the representation of woman. In fact, the paper asserts it as a land mark or an icon of the images of woman and the body (without organ) which is able to link the past and the contemporary works of art into its own position in the history of art. In another words, it becomes the bridge between the representation of a woman between the past and the present.

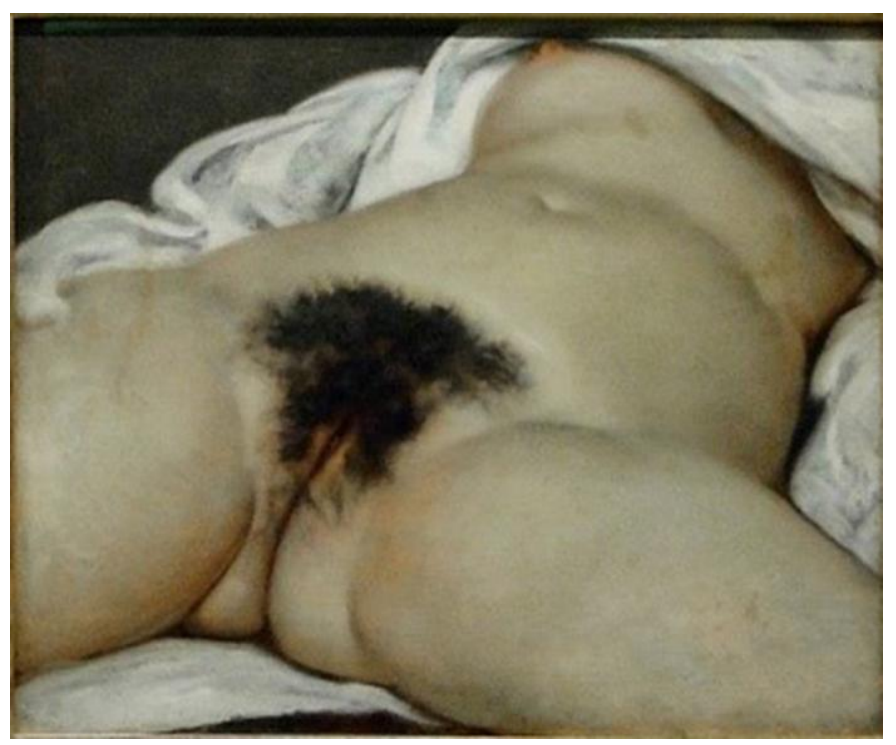

Figure 13. Gustave Courbet, Origin of the World, 1866

On this basis, the recent paintings by Anish Kapoor (Figure 14) evoke a sense of the flesh which has wetness of the blood and questioning of the beauty of the body. How these works become a statement of trauma is that the way he has been able to manipulate the materials in terms of creating a narrative sense of trauma. His works stand as encounters of the inside of the body which was covered by the layers of the skin which is seductive. The hidden thing under the seductiveness is the brutal and fluid interior of the body that can be theorized or re-conceptualized as the Real - trauma.

Monumentalizing the interior of the body by extending its actual limit physically and psychically and conceptually and perceptually the work produces a sense of trauma. The fragment which asserts again the incompleteness represented here has the power of taking the viewer into the painting. In fact, this works plays beyond the context of gender construction. Therefore, the act of turning it inside out can be read as a metaphor for trauma. In fact, Kappor's statement of the flesh is a recalling of Alberto Burri's works (Figure 15) that enormously speak about the trauma through his material transformation and juxtaposition of simplicity and complexity. In another words, the chaos and control is apparent in his works. In fact, Burri's works become a clear statement of trauma in terms of their relationships to the past and present in the context of producing the works. In addition his 
practice as a doctor reappears in the work. That is also asserting Fontana's intervention to the surface, skin ... etc.

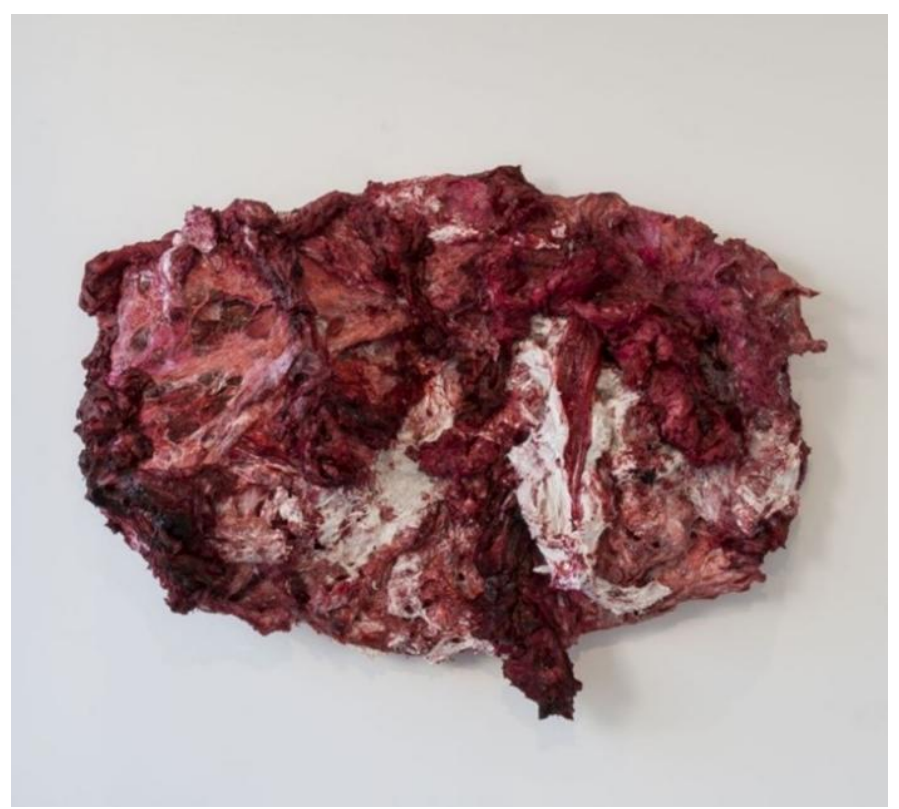

Figure 14. Anish Kapoor, Installation, 2013, Silicone and Pigment

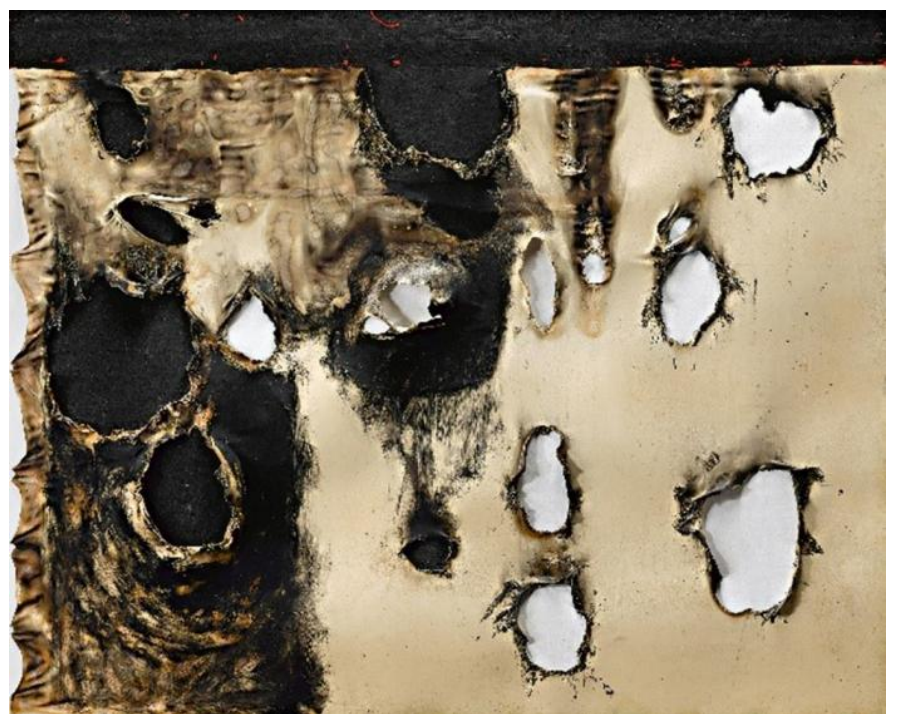

Figure 15. Alberto Burri, Plastic Combustion, 1958

Similarly, the brutal meat body that exists under the seductive-sexy covering layer of the skin is unveiled in the head of the artist made of using the artist own blood. Marc Quinn's self-portrait (Figure 16) can be clearly seen as a reminiscence of the individuality even after removing the skin which had acted as a protective shield of the interior from the attached structure of the body. In fact, the work becomes the Real in terms of material and content which is harmonized in a classical way. On the other hand, Marc 
Quinn's head reminds us of the visual essence of Francis Baconian's notion of the form (Figure 17). At that point, Bacon's approach is to capture the subjectivity of the person rather than the outer appearance of the face. The actual presence of the paint tells about the presence and absence of the figure. His handling of the paint on the base of the structure reveals this uneasiness of recognizing the figure - trauma.

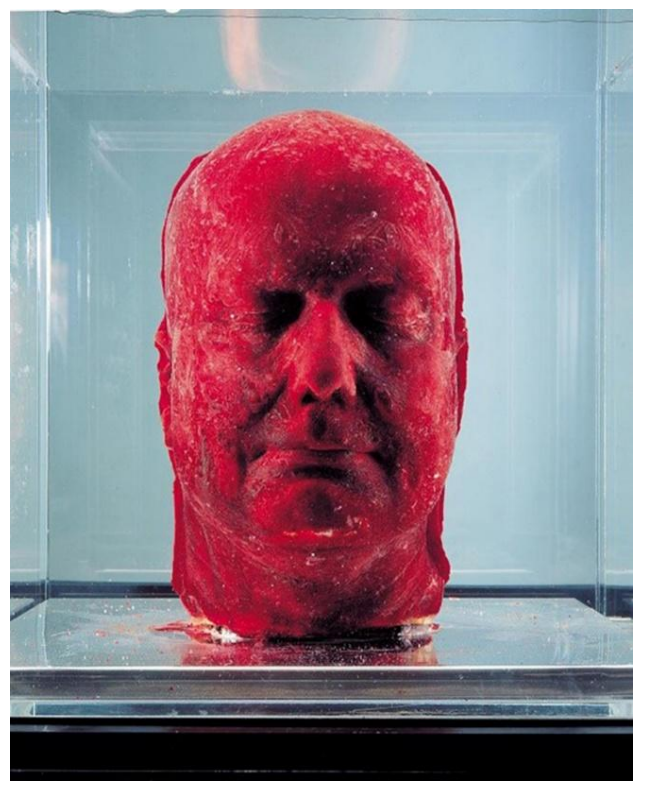

Figure 16. Marc Quinn, Self, 2006 artist own blood
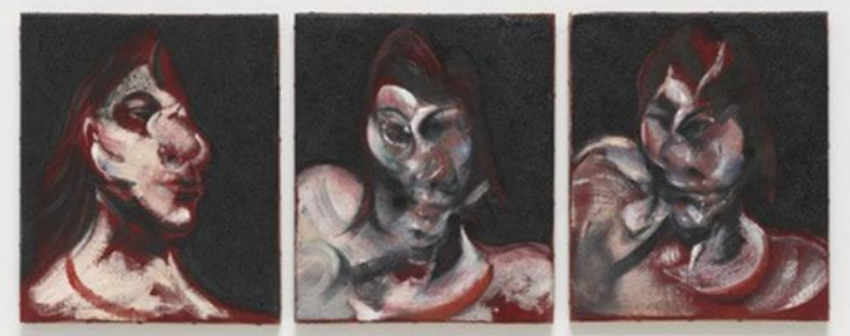

Figure 17. Francis Bacon, A study for a portrait Henrita Moraes (detail)

In addition, the fact that the trauma has different embodiments and is proved by the series of the photographs created by Andre Serrano in 1992 which is able to evoke a sense of the trauma. This piece becomes a trauma to the art world in terms of its title and the material juxtaposition. In particular, talking about the idea of representing the body with using the bodily fluids as a material this piece is significant. Serrano's The Piss Christ (Figure 18) is one of the best examples for this, where it has the artists' own urine in a tank in which he puts a statue of Jesus's crucifixion. It is that this paper's theories on this particular use of bodily fluid that connects to representation of trauma in 
the sense of the absence of the body, but present a part of it that also produce from the body. In this sense, the trauma is not out there, but it exists within us. ${ }^{6}$

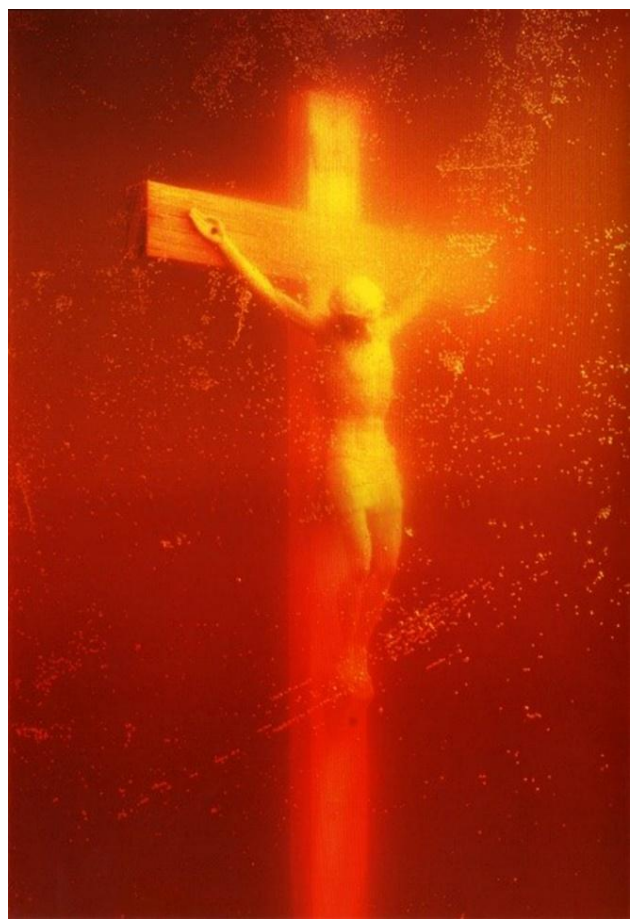

Figure 18. Andrea Serrano, the Piss Christ, 1992, artist's urine, the statue of the Crucifixion, tank

\begin{abstract}
Absence of Trauma
As it is mentioned in the previous sections of this paper, the absence is a concept that forms the representing of the trauma in the works of art. On this context, by considering the Land Art practice as an extension of the genre of the $17^{\text {th }}$ Landscape Painting (Figure 19), it has an extraordinary capacity in producing new meanings and interpretation of human's conditions. Michael Heizer's minimalistic works (Figure 20) has been able to make statements of conditions of human psyche. The geometric four negative forms (Cub, Cone, trough and inverted truncated cone) placed on the ground (now at the Dia's museum in New York) made of weathering steel becomes a presence of the nothingness literally. Yet, the absence as a focal meaning of this work, it produces a sense of fear, danger and uncertainty in the experience of the work. In this sense, it is a juxtaposition of unsignifiable presence and
\end{abstract}

6. Andre Serrano, "Photography, Art and Politics," New York Academy of Art, Art and Culture Lecture Series (New York, 2014). 
recognizable geometric colossal negative forms. Also it has a power to make the viewer's gaze inward to the deep level of the earth, but nothing to see there, which condition implies a signification of psychic trauma. The visual evidence of Hazier's works creates a concept of Orifice that exists in the body and also could in the psyche. Indeed those four negative forms permanently dug on the ground and can be seen as a site of archaeological excavation. On the other hand, making a hole by digging the ground becomes a metaphor for the death. And the work titled Ornament I by Barnet Newman (Figure 21) has a sense of trauma that is present not as a window but rather as a space that seems extremely closer to the viewer's sight which is similar to the works titled the Origin of the World (Figure 13). The fact that closeness is able to create a sense of confrontation to the viewer with the thing that is indescribable, becomes a sign of trauma.

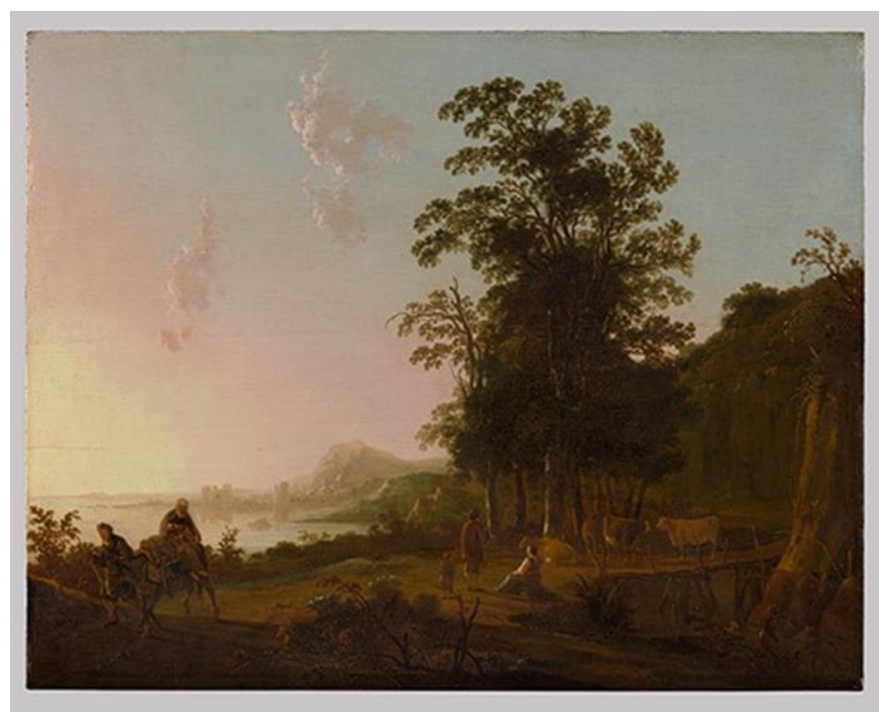

Figure 19. Aelbert Cuyp , Landscape with the Flight into Egypt, 1650

By concerning to unveil the hidden life in the works of arts, the incompleteness and the displacement of the form in the representation can be read as characteristics of representation of trauma. In fact, the phenomenological hypothesis is perhaps insufficient because it merely invokes the lived body. ${ }^{7}$ On this context, returning to some works by Anish Kapoor represents these ideas through the series of his works based orifices (Figure 22) which evokes the sense of the absence of the body and the incompleteness. Which also links with the works of Haizer (Figure 20), discussed in the previous section of this chapter. Indeed the deconstruction of the body and its organism seem to be a representation of trauma in the sense of unobvious presence.

7. Ibid., 39. 


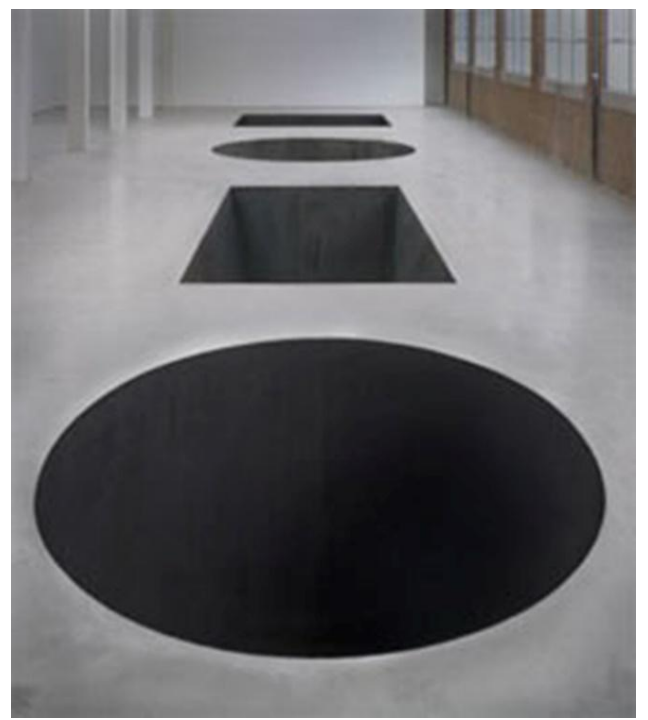

Figure 20. Michael Hazier, North, East, South and West, 1967 - 2000

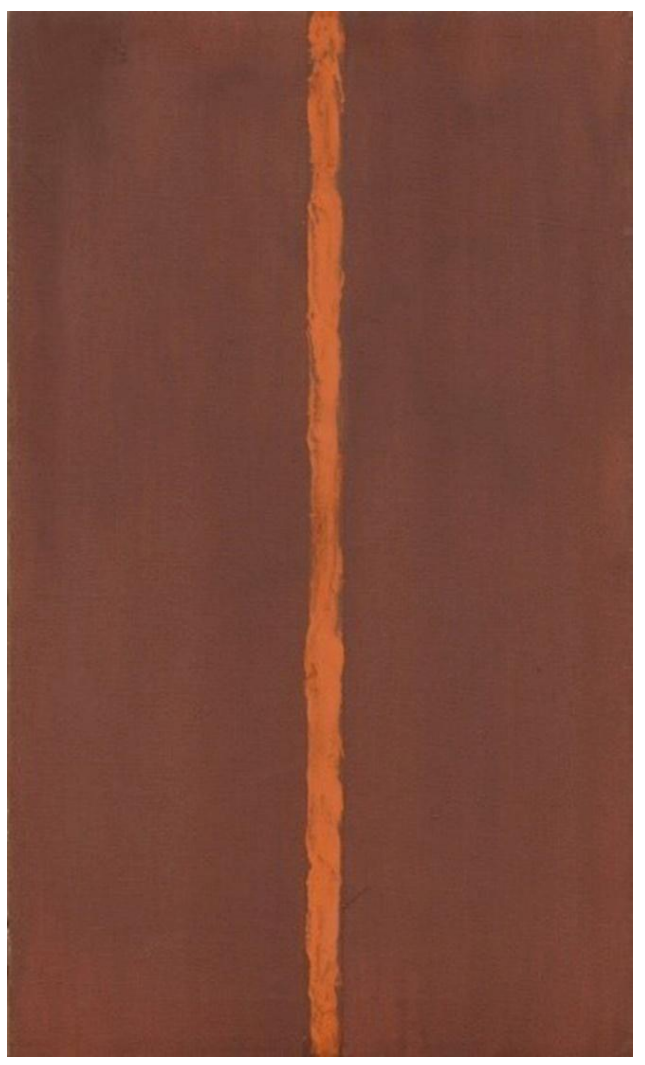

Figure 21. Barnett Newman, Ornament I, 1948 


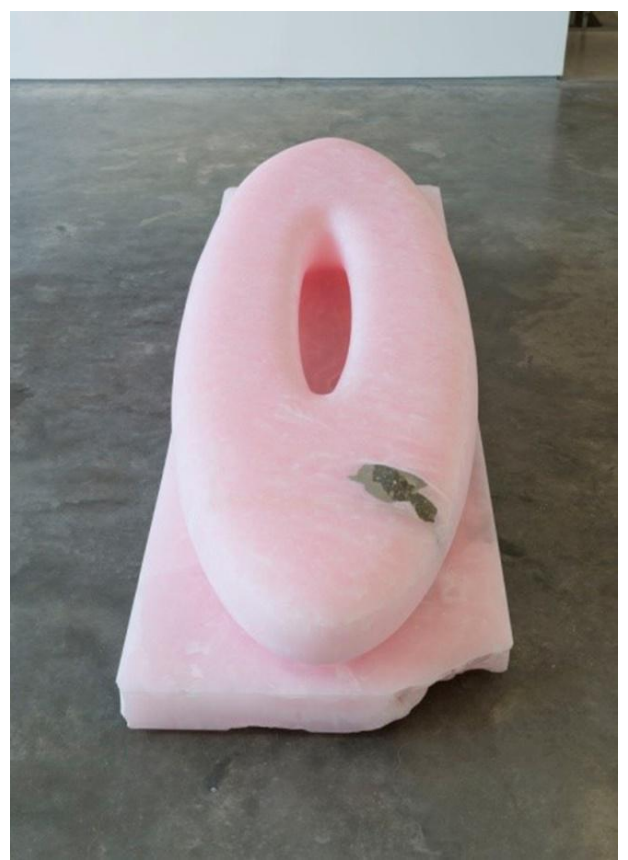

Figure 22. Anish Kapoor, Pink Onyx, 2013

The sculpture entitled Fat Chair (Figure 23) by Joseph Beuys produces the same sense with the disordered body. The fat literally represents the idea of the body, fleshiness, but the absence of the complete body can be read as a representation of trauma in the form of absence.

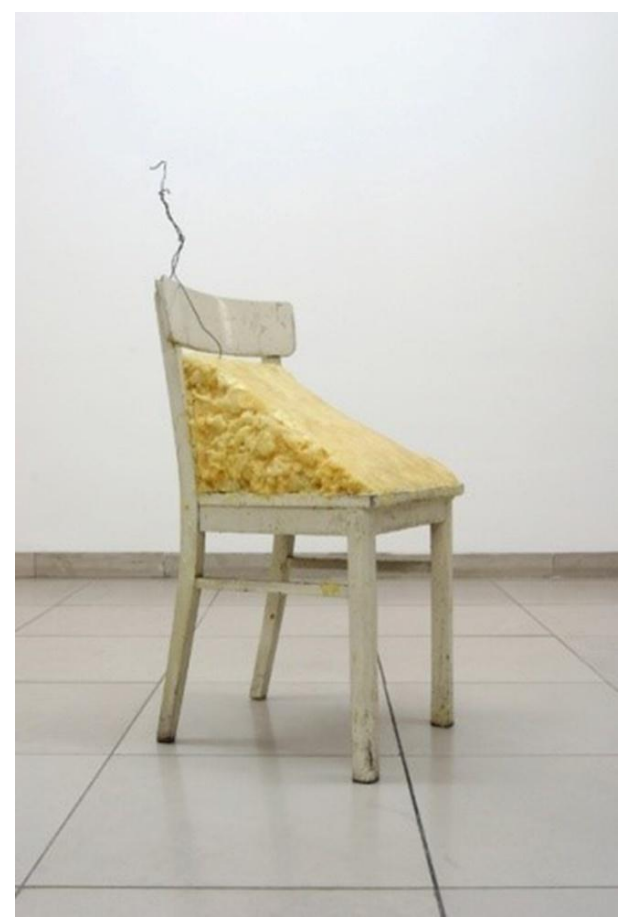

Figure 23. Joseph Beuys, the Fat Chair, 1964-85, Wood, Glass, Metal, Fabric, Paint, Fat and Thermometer 


\section{Gendered Trauma}

As it is earlier stated the trauma always has characteristics of being belated in the presence. Gendered trauma primarily focuses on exploring the works of art created by female artists. In the paper the relation between the concept of gender identity and the representation of the trauma will be discussed. Significantly, these artists are able to bring forward new means of aesthetic in the process of art making. In the conception of the body-psyche relation in the work by Gina Pane engages with the real act or event that creates trauma in addition to the subject of the works that the artists talk about. For instance, the performance entitled Action psyche (Figure 24) is a juxtaposition of meaning of the human subject and object. Particularly, in her case, it is about the body and the conception of the femaleness. At the same time, the interaction between subject and object in this work becomes an implication of a sadomasochistic desire in which the trauma seems transmissible. She is able to create a psychological charge in the experience of the work by wounding her body by herself, particularly the naval: the center of the body in a classical anatomical structure. The subject of this performance is able to challenge the traditional notion of the beauty and the passivity of the femininity in the history. Physically opening the body transmits the psychic trauma into the viewer's space while the event already has a meaning of physical trauma. Indeed, in the Lacanian psychoanalytical sense, this act tends to be read as a perversion of subject that is going beyond the pleasure principle. In which, it encounters with pleasure and pain; jouissance. ${ }^{8}$ In addition, what this cut means in terms of the symbolic formation of the body into the gender formation is that it stands for the means of the castration complex while it creates a passage to the womb of her body through the cutting around the naval in a crossed shaped where the two bodies are separated.

8. Dylan Evans, An Introdutory Dictionary of Lacanian Psychoanalysis (London: Routlede, 1996), 139. 


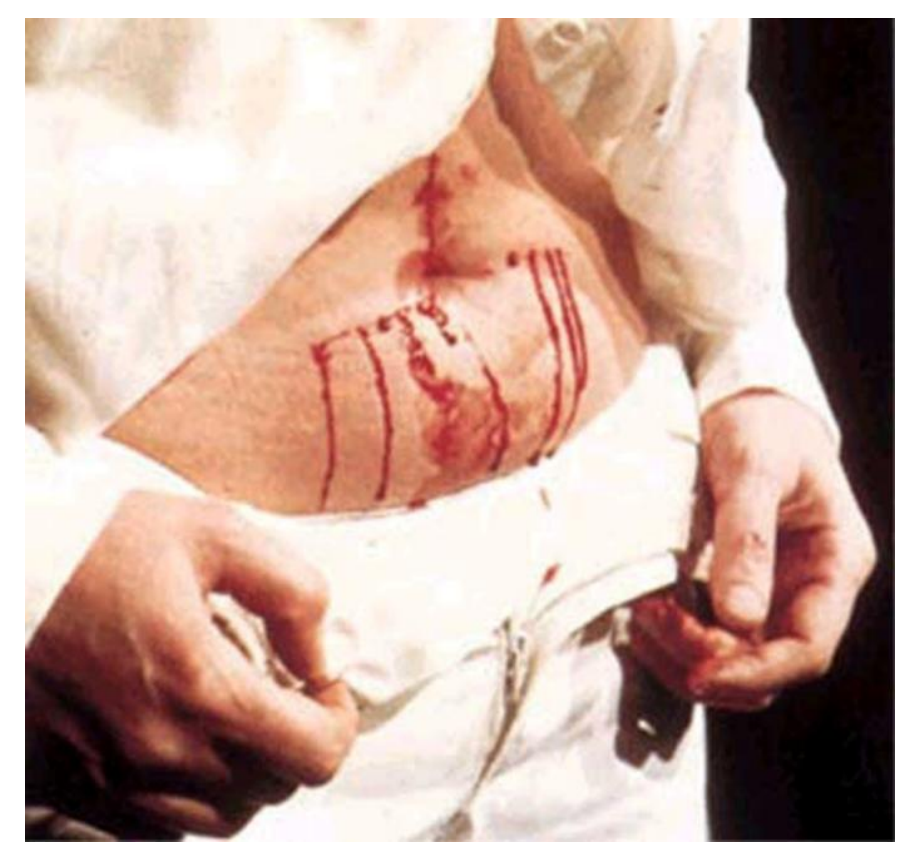

Figure 24. Gina Pane, Action psyche, 1974

Furthermore, Hanna Wilke's work has significant meanings in creating a sense of trauma. In particular, the series of works she did on the titled of IntraVenus (Figure 25) clearly represents subjects such as the life, death and memories based on a narcissistic psychical expression on her own body and its changes with the loose of that Venus like beauty within the time line. In which, it creates a physical and a psychical link to her past work titled from so help me Hanna (Figure 26) which is based on the subject of her mothers' body. Juxtaposing a photograph of herself and a photograph of her mother with mastectomy, this work becomes a representation of inter-subjective connection between her and her mothers' body which insisted on traumas of the loss of the loved object. ${ }^{9}$ In fact, these two photographs seem speaking as a bodily transformation of the same person: narcissistic beauty is being converted, which fact significantly makes the past present and also as an event that could be belatedly present in the future. The actual conversion of Hanna's body that happened later in her life will be an example for this. In fact as a whole thing, perceptually and conceptually this work becomes a representation of trauma.

9. Amelia Jones, Body art Performing the subject (University of Minnesota, 1998), 188. 

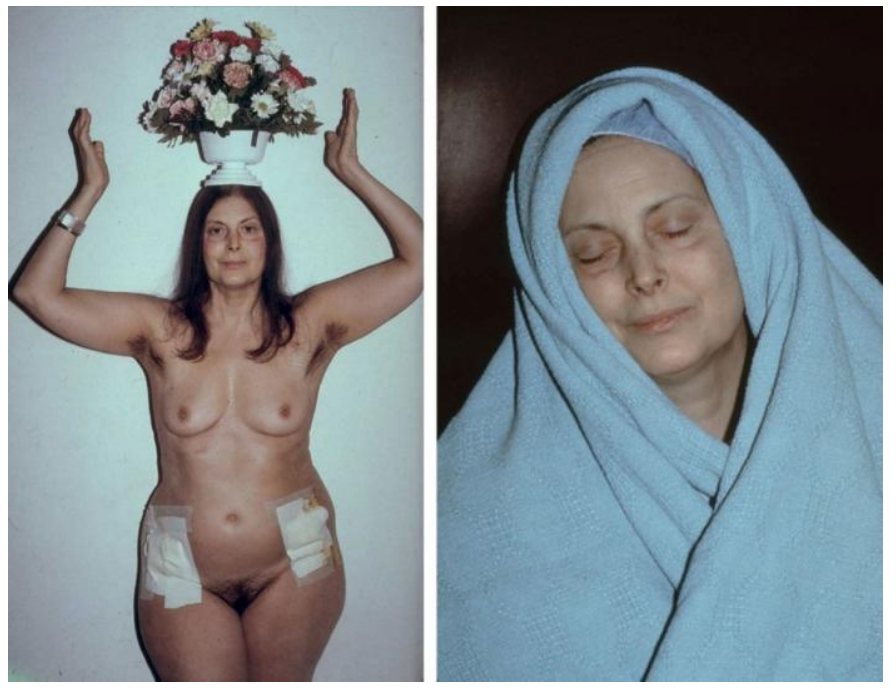

Figure 25. Hanna Wilkes, Intra Venus, 1992
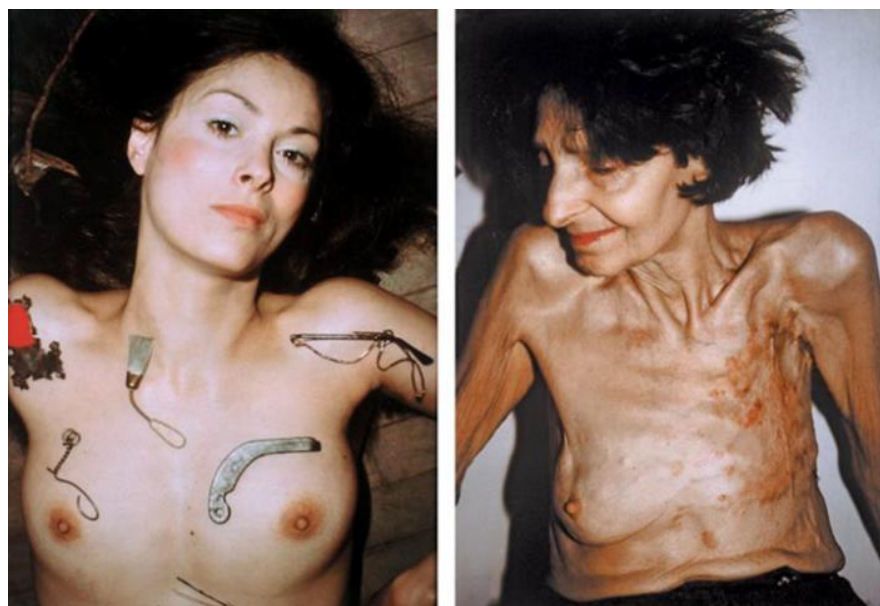

Figure 26. Hanna Wilkes, So help me for Hannah, photograph, 1978-81

\section{Trauma Body}

Moreover, the concept of the abjection could be read as a form of representation of trauma in the works of art. Julia Kristiva describes the abject as that which disturbs identity and order and does not respect order and rules. ${ }^{10}$ In this sense it is something that opposes to the notion of classicism in the representation. The works created by Rona Pondick has an implication of trauma in terms of distortion of the identity and the body that she created. The mouth (Figure 27) is seen as deconstruction and fragmentation of the body as a whole thing. The one unit represents a sense of trauma while the whole

10. Thomas McLerran and Jennifer Pattin, Art Words (New York: Routledge, 1997), 1. 
thing has the same uncanniness already. So, this juxtaposition creates a condition of the absence and the presence of trauma and its repetition.

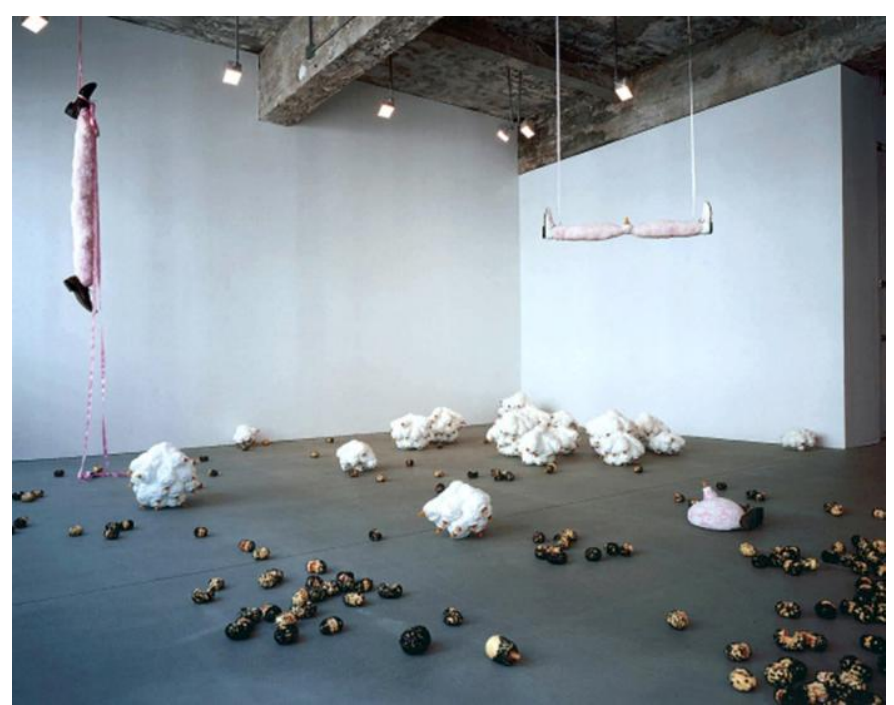

Figure 27. Rona Pondick Mouth, 1992-93

KiKi Smith's works have a power of producing meanings of trauma in a way. The work entitled the tale (Figure 28) shows a kneeling female body with a very long tale. The combination of the tale and human body is so intense perceptually and conceptually. The juxtaposition of this relationship emphasizes a sense of disturbance in a way. This hybridization makes the body traumatic in the presence.

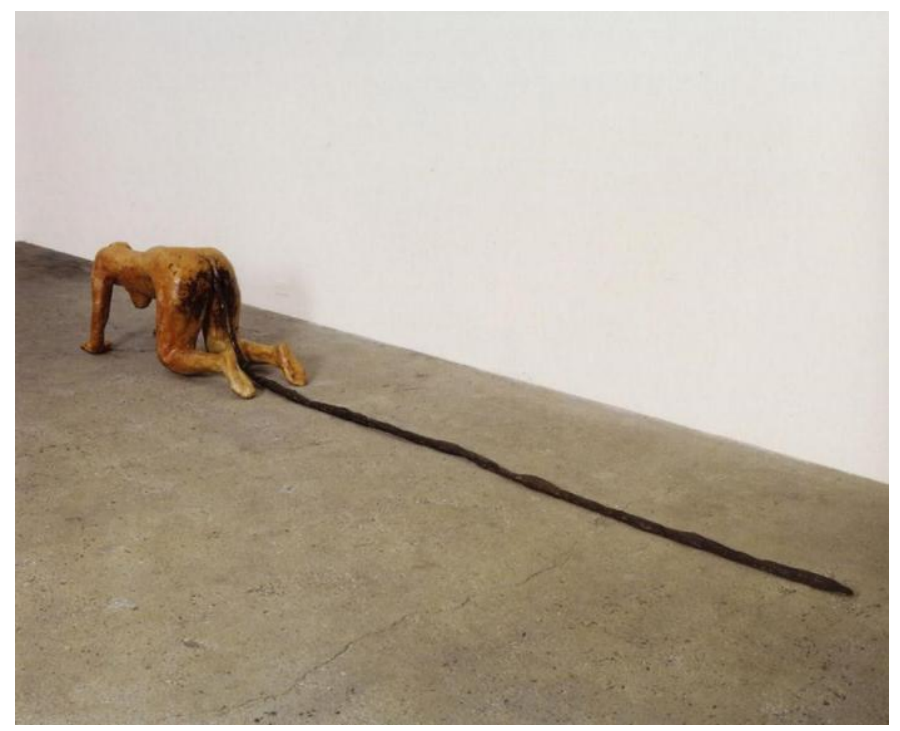

Figure 28. Kiki Smith, the Tale, 1992

The encounter of different bodies, gender and psyches unexpectedly and even within a certain context is able to create a trauma. The performance 
titled The artist is present (Figure 29) by Marina Abramovic which took place at the Museum of Modern Art in New York in the United States evokes a sense of trauma in terms of the content of the work. It is just a performance where the artist sits on a chair for several hours per day facing someone who sits in front of her. The performance is nothing about making any particular action, but it is basically remaining consciously on the gaze to each other for a long period of the time. So, being looking at each other doing nothing creates the presence of a heaviness of the nothingness, it is proved by the fact that it becomes encounters of phenomenological and psychological presence-ness that both the sitter and the artist are affected by the unbearable silence. So, that the unsigifiable condition creates the presence of trauma which is proved mostly by the sitter's bodily reaction to the performance. For instances, crying, tearing ... etc.

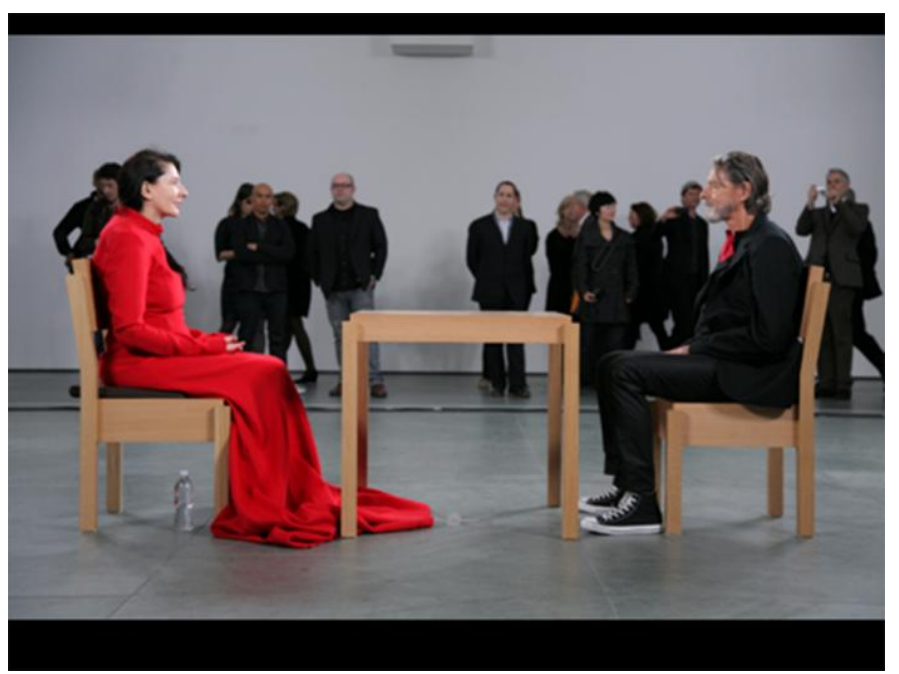

Figure 29. Marina Abramovic, the Artist is present, 2010

\section{Trauma and Me}

This section mainly concerns my own art practice that is based on the theme of trauma. My approach to the theme is based on my personal and social experiences and my attempt to re-conceptualize that experience through the language of painting. Extensively, my work is governed by two main events: one is my childhood memories of the civil war and the terrorism that happened in Sri Lanka in 1988-89 and since 1979 respectively and the second is the death of the Father (my own). And at the same time, the impact of the late capitalism within the context of the Post-Colonialism is significant in understanding human conditions and relationships in such a context. In addition, the concept such as the family, identity, gender, subjectivity will be 
represented in my works which also evokes a sense of the historical and personal traumas. ${ }^{11}$

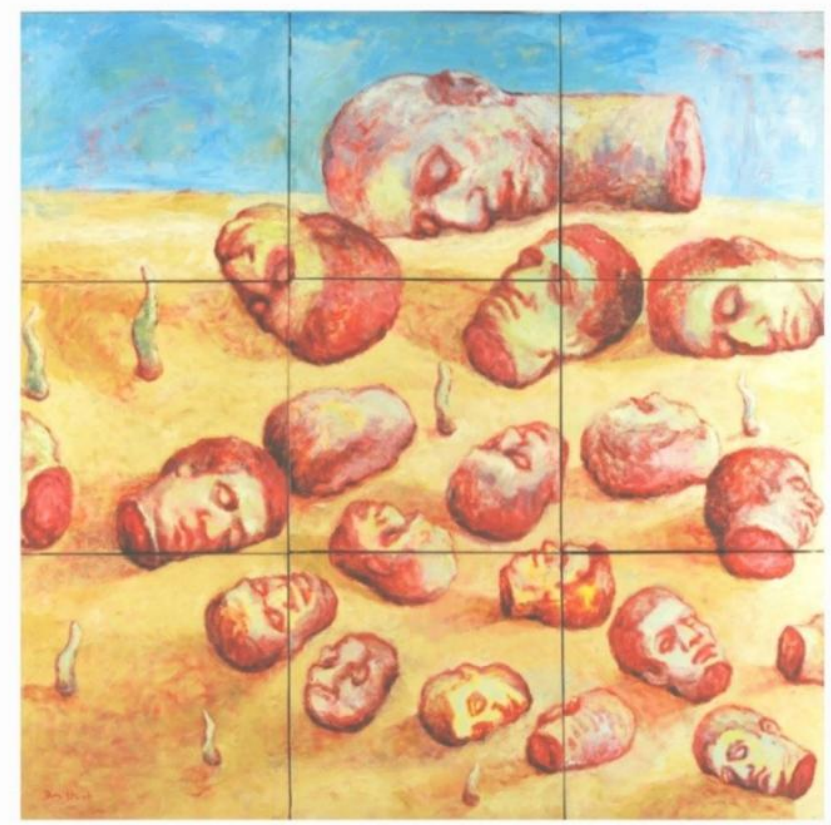

Figure 30. Dumith Kulasekara, Traumatism, 2006

The painting entitled traumatism (Figure 30) is based on true stories that I heard from the experience of my mother who has seen many decapitated young people on a road near to the city I was living in. The words of my mother on the incident were a deep effect on me in imagining the Real situation of the incident. So the paintings with the heads which are represented as self-portraits on an uncertain ground reflect that psychic trauma. The painting reveals my interest on the flesh and its brutal representation which has been discussed in the previous chapters. The repetition of signs of decapitation is significantly represented in this work. In fact, the masochism is a condition that I have been interested in working on. It is more about an act or an event rather than a condition within a posttraumatic condition. The painting entitled Masochism (Figure 31) implies of being incomplete by the decapitation by him. In fact, these wounded pieces of the bodies become an implication of castration which can also be considered as a sign of femininity. ${ }^{12}$ In addition, the historical sign of the trauma in the rib (Figure 10) is intentionally depicted in the body.

11. Dumith Kulasekara, The Symbolical Impossibility of Disavowing Trauma; Catalogue of the second solo exhibition (Colombo: Exhibition catalogue), (The Pradiseroad Gallery).

12. Linda Nochlin, Representing Women (New York: Thames and Hudson, 1999), 13. 


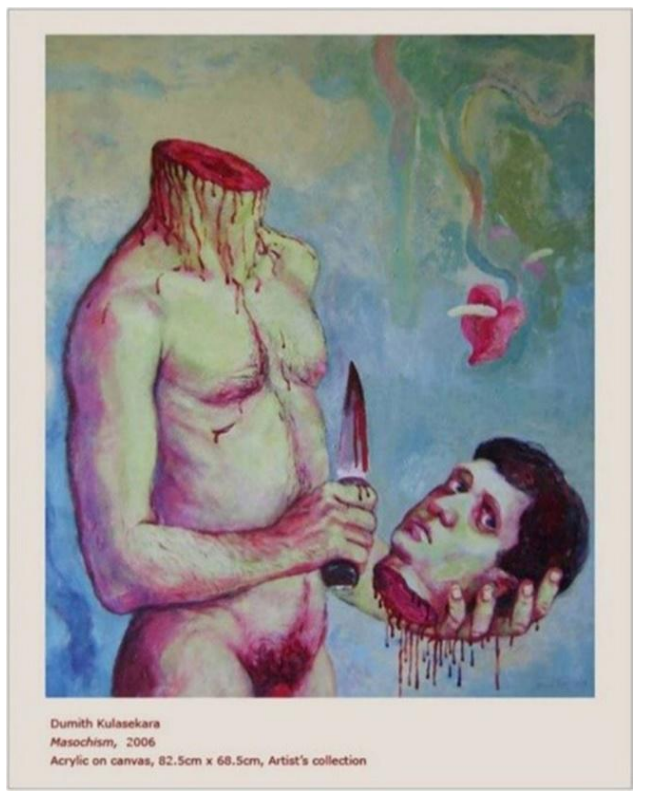

Figure 31. Dumith Kulasekara, Masochism, 2006

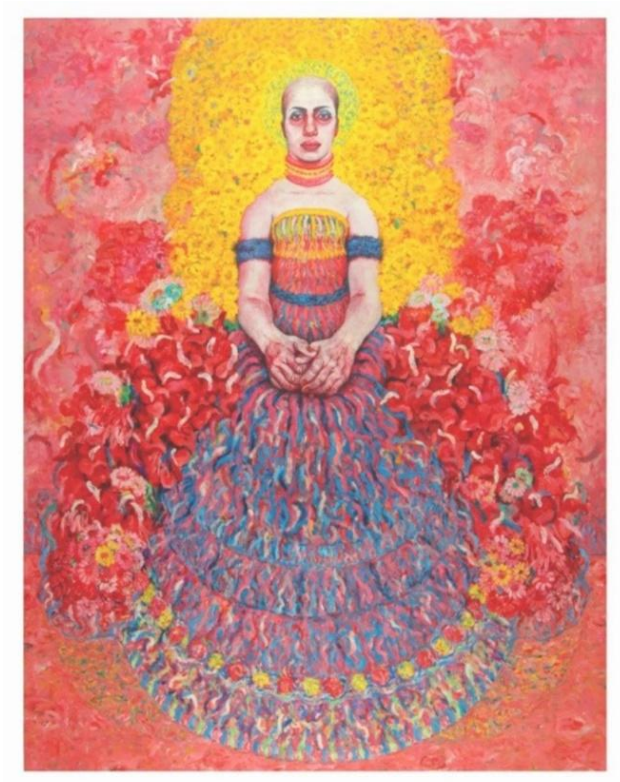

Figure 32. Dumith Kulasekara, Meaning of Wo-men...?, 2008, Paradiseroad Collection, SL

In this sense, the painting; the meaning of wo-man ... ? (Figure 32) represents a woman sitting in floral atmosphere and has a sense of pain and pleasure and beauty and ugliness as well. So, this painting reminds us of the history of Byzantine icon paintings in the $12^{\text {th }}$ century that are symmetrical in the design. I was interested in bringing the unspeakable condition of the trauma (Figure 33). Indeed the head with growing penises fallen on the ground is another attempt to represent the concept of trauma through my 
practice. Fragmenting the body and representing its incompleteness, I try to evoke a sense that cannot be understood within the language. At the same time I deeply think about my own iconography in creating works. For instance, the penis is a predominant element in my works that stands as a metaphor for the absence of the father which in a sense directly links to the death of my own father. The work titled the death of the father (Figure 34) was created with the purpose of producing that meaning.

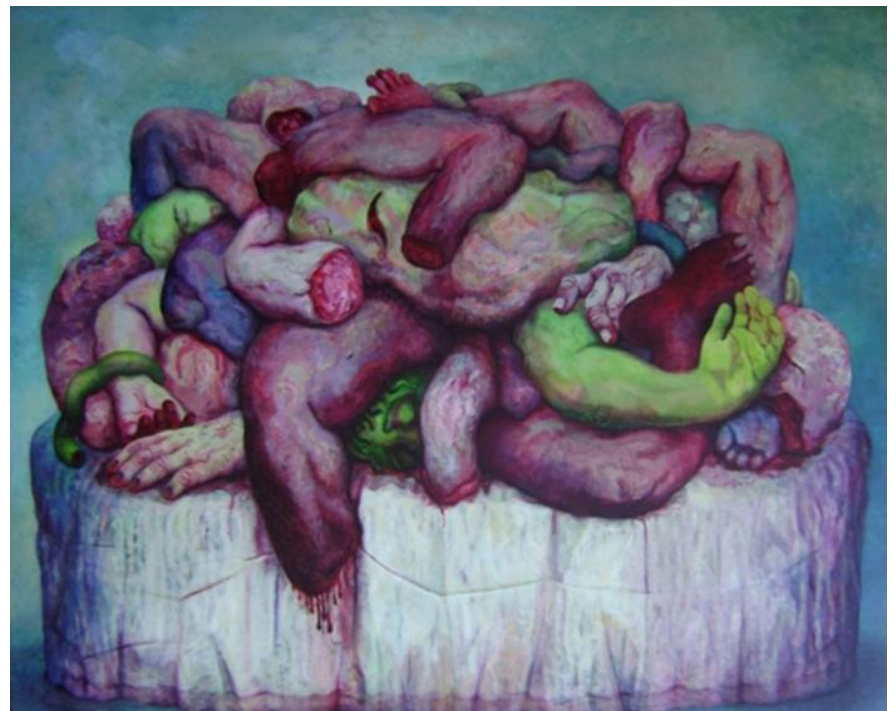

Figure 33. Dumith Kulasekara, the Death of the Father, 2008, Artist's collection, SL

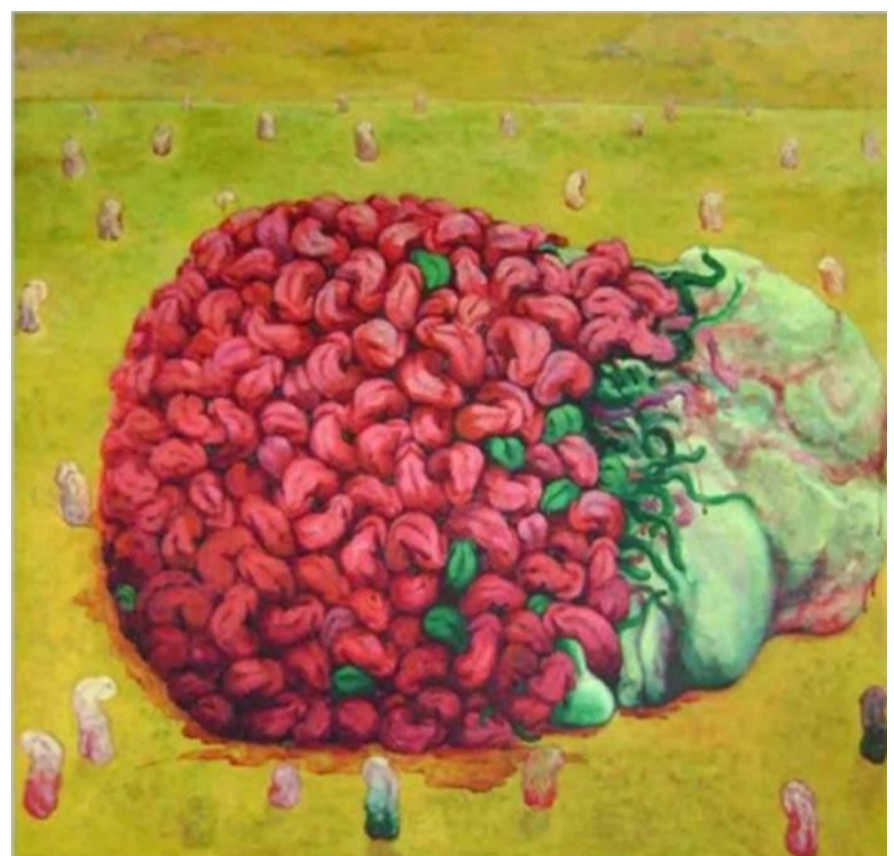

Figure 34. Dumith Kulasekara, the $18^{\text {th }}$ of May and Reminiscence of Masculine War, 2010-11, Paradiseroad Collection, SL 
The unspeakable condition of trauma that presents in the encounter with it is one of the important facts that I deeply consider in creating my works. For that, I am strongly concerned about the perceptual and conceptual construction of the works. The repetition of the presence of the front view of the bodies and objects in my works has a visual relation to the concept of the trauma. The collection of the fragmented bodies represented in the work entitled the eighteenth of May and reminiscences of masculine war (Figure 34) becomes my personal statement and reaction to the war and the so-called belief of its ending on eighteenth of May in 2010 in Sri Lanka. I placed the self-portrait at the center of the composition to signify the presence of trauma. Indeed, it becomes a result of my visual research on the theme. In fact, my works is autobiographical in a sense. I include my family members (my wife, my mother and me and very recently my daughter) into my work within the context of the absence of the (my) father. The painting entitled Oedipal in Crisis (Figure 35) significantly represents the perpetual present of the trauma in an intersubjective context.

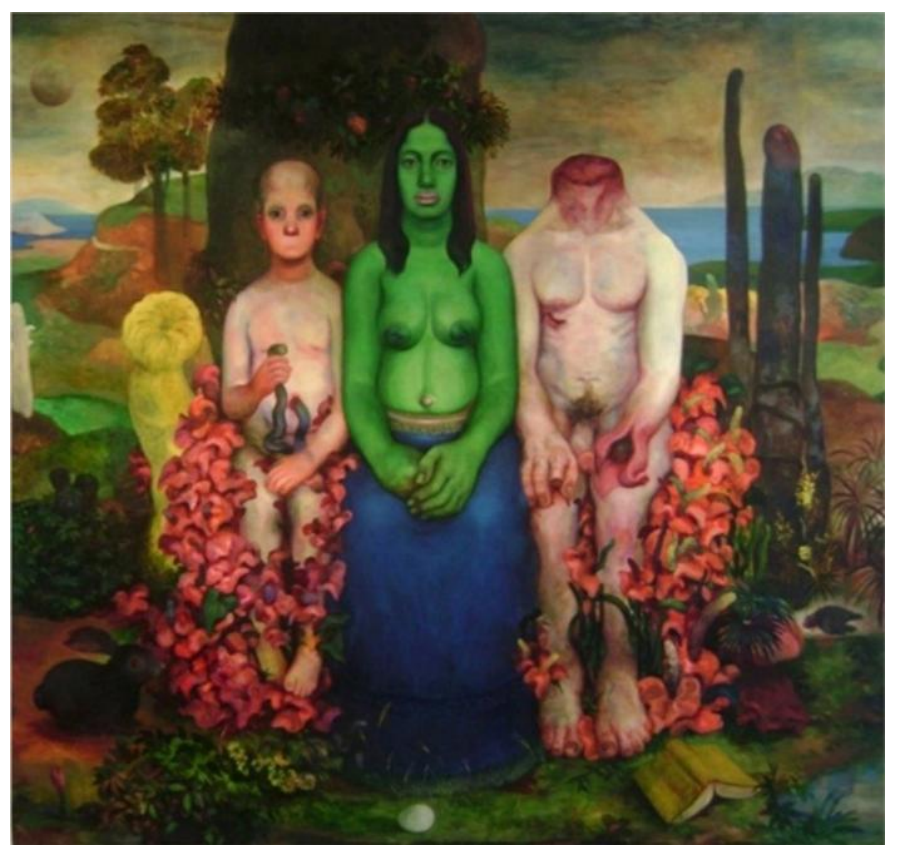

Figure 35. Dumith Kulasekara, Oedipal in Crisis, 2011, private collection, SL

In addition, the work titled the Polymorphous (Figure 36) is not a representation of a subject or an object, rather it becomes an abjection which evokes a sense of traumatic disturbance. This image becomes a metaphor for trauma. By its title, the trauma has a different embodiment which shows in this picture. Furthermore, the series of the works I produced on the theme represent a visual beauty in terms of the color and texture. By using such a vibrant color palate I wanted to play in between the pleasure and pain as sublimity includes both pain and pleasure. 


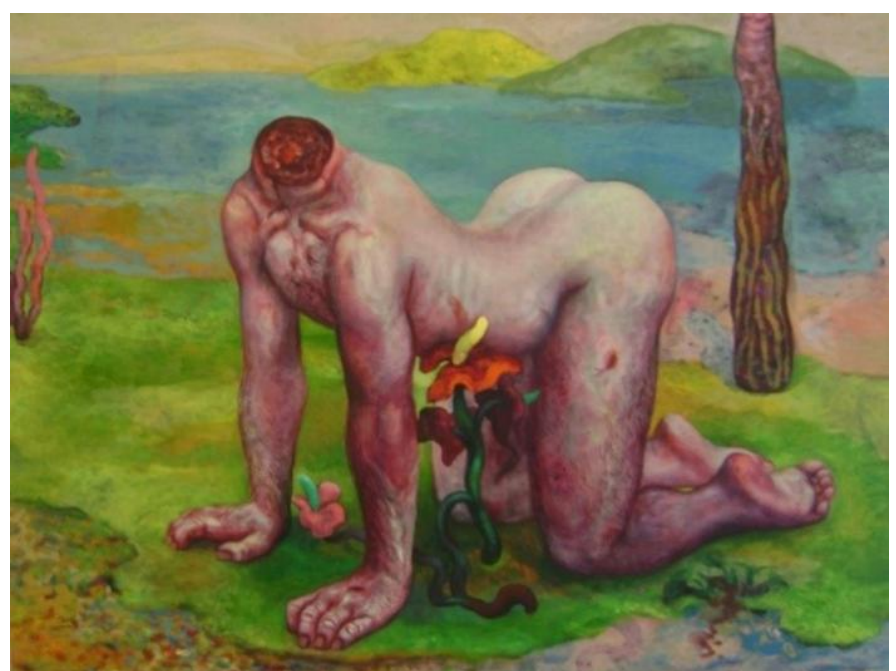

Figure 36. Dumith Kulasekara, polymorphous, 2010, Paradiseroad collection, SL

\section{Bibliography}

Battersby, Chritine. 2007. The Sublime, Terror and Humnan Difference. New York: Routledge.

Deleuze, Gilles. 2004. Francis Bacon; The logic of Sensation. Mineapolis: University of Minnesota Press.

Evans, Dylan. 1996. An Introdutory Dictionary of Lacanian Psychoanalysis. London: Routlede.

Jones, Amelia. 1998. Body art Performing the subject. University of Minnesota.

Kulasekara, Dumith. 2011. The Symbolical Impossibility of Disavowing Trauma. Colombo: Exhibition catalogue (The Pradiseroad Gallery).

McLerran, Thomas Pattin and Jennifer. 1997. Art Words. New York: Routledge. -. 1999. Representing Women. New York: Thames and Hudson.

Pollock, Grisellda. 2013. After Affect - After Image: trauma and aethetic transformation in the virtual museum. New York: Manchester University.

Polock, Grisellda. 1999. Differencing the Canon; Feminist Desire and the writing of art Hisotries. New York: Routledge.

Serrano, Andre. 2014. "Photography, Art and Politics." New York Academy of Art. Art and Culture Lecture Series. New York. 
